\title{
Semiconductor optical amplifier-based all-optical gates for high-speed optical processing
}

\section{Stubkjær, Kristian}

\section{Published in:}

I E E E Journal on Selected Topics in Quantum Electronics

Link to article, DOI:

$10.1109 / 2944.902198$

Publication date:

2000

Document Version

Publisher's PDF, also known as Version of record

Link back to DTU Orbit

Citation $(A P A)$ :

Stubkjær, K. (2000). Semiconductor optical amplifier-based all-optical gates for high-speed optical processing. I E E E Journal on Selected Topics in Quantum Electronics, 6(6), 1428-1435. https://doi.org/10.1109/2944.902198

\section{General rights}

Copyright and moral rights for the publications made accessible in the public portal are retained by the authors and/or other copyright owners and it is a condition of accessing publications that users recognise and abide by the legal requirements associated with these rights.

- Users may download and print one copy of any publication from the public portal for the purpose of private study or research.

- You may not further distribute the material or use it for any profit-making activity or commercial gain

- You may freely distribute the URL identifying the publication in the public portal 


\title{
Semiconductor Optical Amplifier-Based All-Optical Gates for High-Speed Optical Processing
}

\author{
Kristian E. Stubkjaer
}

Invited Paper

\begin{abstract}
Semiconductor optical amplifiers are useful building blocks for all-optical gates as wavelength converters and OTDM demultiplexers. This paper reviews the progress from simple gates using cross-gain modulation and four-wave mixing to the integrated interferometric gates using cross-phase modulation. These gates are very efficient for high-speed signal processing and will open up interesting new areas, such as all-optical regeneration and high-speed all-optical logic functions.
\end{abstract}

Index Terms-Add/drop multiplexer, optical gate, optical processing, semiconductor optical amplifier, wavelength converter.

\section{INTRODUCTION}

$\mathbf{F}$ OR YEARS, there has been a desire to realize all-optical computers using digital optical elements. Clearly, this is very ambitious since optical elements lack the packing density of electronic gates because of the much shorter interaction length of electrons compared to photons. Nevertheless, it is very realistic to aim at simple optical-signal processing in telecommunication networks. The requirements are not for massive processing, but rather the possibility of simple optical processing at bit rates close to or beyond the bandwidth of presently available electronics, i.e., $40 \mathrm{~Gb} / \mathrm{s}$ and above. The all-optical processing is especially attractive in the high-capacity core networks where we want to avoid opto-electronic conversion. The all-optical functions needed in add-drop and cross-connect fabric are wavelength conversion, add-drop-multiplexing (wavelength and time), clock recovery, regeneration, and simple bit-pattern recognition.

For most of these functions, we need simple gates that can be controlled optically, as shown in Fig. 1. A gate used to modulate a CW signal or a pulse train can function as a wavelength converter, or part of an optical regenerator, respectively, whereas gating of an optical input signal can be used for time demultiplexing, e.g. Moreover, optical elements that can perform simple logic operations such as AND or XOR will be useful for routing functions for example.

All optical gates are realized by optical nonlinearities in both glass and semiconductor material and are relying on mechanisms, such as four-wave mixing, cross gain, cross-phase and cross-absorption modulation, or combinations of these.

Manuscript received October 9, 2000.

The author is with the Research Center COM, Technical University of Denmark, DK-2800 Lyngby, Denmark (e-mail: ks@com.dtu.dk).

Publisher Item Identifier S 1077-260X(00)11552-7.

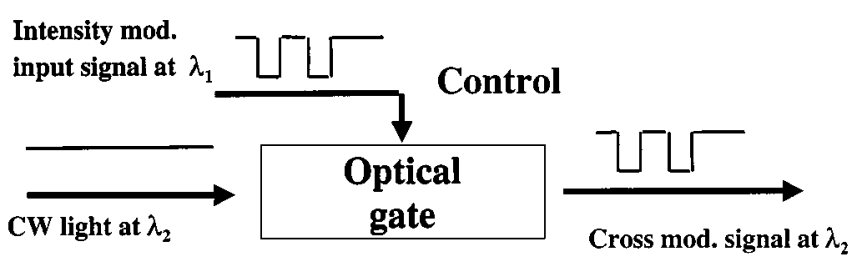

(a)

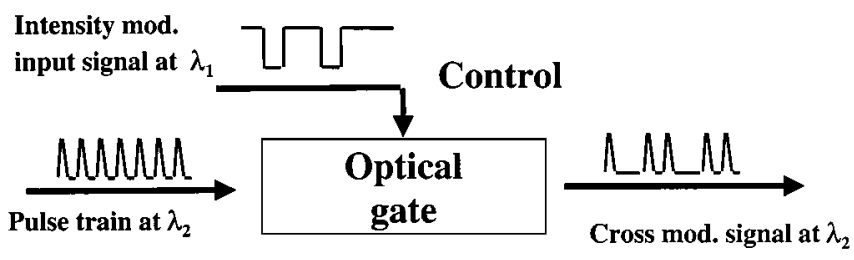

(b)

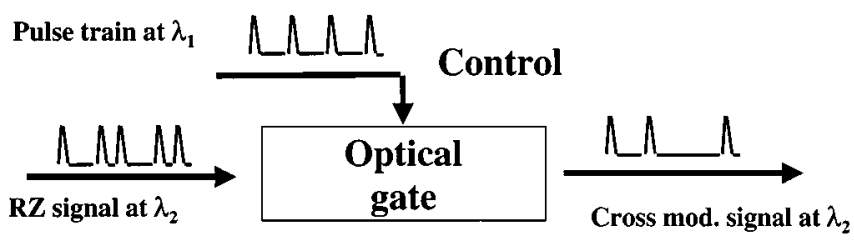

(c)

Fig. 1. Schematic of optically controlled gate used for: (a) Wavelength conversion by gating of CW light. (b) Regeneration and wavelength conversion by gating of clock pulses. (c) Demultiplexing-sampling by gating of optical signal using clock pulses.

Depending on the transfer function of these gates, inverted or in-phase output signals result (see Fig. 2). Clearly, we need modules that

1) operate at low optical power levels;

2) are easily adjustable to the system bit rate and to the transmission protocol;

3) are polarization independent; and

4) can be cascaded in several stages.

This paper is primarily devoted to nonlinear elements based on semiconductor optical amplifiers (SOAs). The history of SOAs is going back to the beginning of the 1980s, where the development effort was clearly motivated by the need for linear amplification in point-to-point systems. Challenges included the realization of low-facet reflectivities and high fiber-to-fiber gains by also reducing the coupling losses (see for example [1] and [2]). With the arrival of the erbium doped 

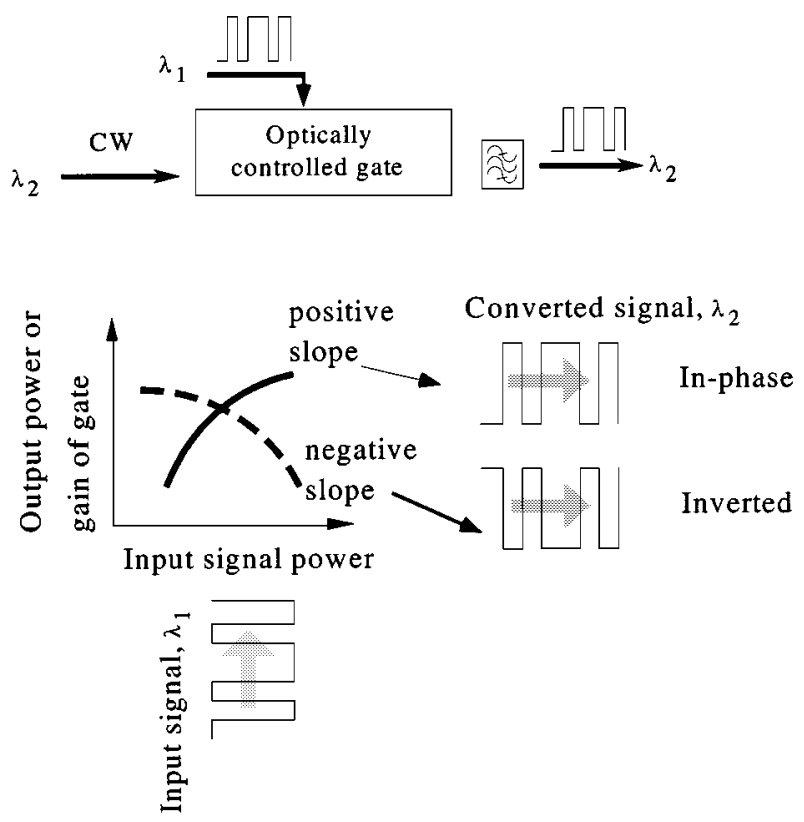

Fig. 2. Schematic of optically controlled gate and the dependency of the output signal on the transfer characteristic of the gate.

fiber amplifier (EDFA) around 1990, the SOAs were, however, almost out-competed as linear amplifiers. The EDFAs featured lower noise levels and also much better crosstalk properties for multichannel amplification, due to the much longer recombination times for the excited states in Er compared to the very fast carrier dynamics in semiconductor material. SOAs still have a potential price advantage over EDFAs since they are powered directly, so they may be useful as amplifiers in access networks. Moreover, they can provide solutions outside the $1500-\mathrm{nm}$ band where fiber-based amplifiers are more difficult to realize.

\section{XGM GATE}

The nonlinear behavior that is a drawback for the SOA as a linear amplifier makes it a good choice for an optically controlled optical gate. First reports of optically controlled SOAgates were made in [3] and [4]. In both cases, cross-gain modulation (XGM) was explored: The input signal is used to saturate the gain and thereby modulate a $\mathrm{CW}$ signal (probe) at the desired output wavelength.

The wavelength conversion application has been a very strong driving force behind the investigations of XGM-gates. By the middle of the 1990s, it was very clear that wavelength division multiplexing (WDM) is a very competitive way to upgrade for higher transmission capacity. Moreover, it became obvious that WDM networks with all optical cross connects will be needed for efficient transport of information, e.g., [5]-[7]. Wavelength conversion-translation within the network or at its interfaces is needed for efficient dynamic transport reconfiguration, high-level restoration, and utilization of the fiber bandwidth [8], [9]. The converters make it possible to assign wavelengths on a link-by-link or a subnetwork basis, thereby relaxing the requirements to the wavelength precision throughout the whole network [8]. Moreover, wavelength conversion eases the recovery from link or node failures by allowing for local rather than global reconfigurations in the network, e.g., [8]-[14]. Thus, there are very good arguments for pursuing efficient wavelength conversion.

The cross-gain modulated (XGM) gate is extremely simple to assemble. It is polarization insensitive because of polarization-independent SOA gain, and it is very power efficient. It also turned out that the gate can be extremely fast, and, by 1998, bit rate capabilities of $100 \mathrm{~Gb} / \mathrm{s}$ were reported [15], [16]. At first glance, it seems impossible to reach this speed due to the relatively slow carrier dynamics with lifetimes in the order of 100 psec [17]. Detailed analyzes can, however, explain the significant role of gain saturation in achieving high speed [18]. The prospects of achieving even higher bit rates look fine with the use of quantum dot material. Pump-probe experiments reveal very fast gain dynamics [19] in amplifiers made from this material.

The XGM gate has a number of shortcomings, such as inversion of the input-control signal and the relatively large chirp of the output signal due to the large gain modulation. Nevertheless, the gate has been used with fine results in a number of switch block experiments, e.g., [20], [21]. Moreover, the gate has been used to pioneer very interesting work on format conversion from RZ to NRZ and vice versa [22]. OTDM to WDM transmultiplexing can also be achieved [23], [24]. The gate has also been used for demonstration of header erasure and replacement in various optical packet switching schemes [25], [26]. It remains an interesting challenge to come up with new combinations of such gates to achieve new functionalities.

SOA gates exhibiting optical bistability have also been realized using SOAs or laser diodes with higher facet reflectivities, e.g., [27], [28]. The bistability is a result of the interaction between the gain and index variations in the resulting cavity. These bistable elements do, however, have limited bit-rate capabilities in the order of $1-5 \mathrm{~Gb} / \mathrm{s}$, making them unattractive compared opto-electronic alternatives.

\section{XPM GATES}

Gates with better performance are achieved by placing SOAs in interferometric configurations, such as those shown in Fig. 3. In these gates, the optical input signal controls the phase difference between the interferometer arms through the relation between the carrier density and the refractive index in the SOAs (cross-phase modulation, XPM); thereby a CW light or a pulse train can be gated [29] or control pulses can be used to gate the input signal.

For stable operation, the XPM converters must be integrated. The first monolithic structures reported [30] were based on Michelson interferometers [Fig. 3(b)], realized by cutting sections out of the $4 \times 4$ space switch with SOAs made by Ericsson Components [31]. An early realization of a two-port Mach-Zehnder structure was based on a back-to-back coupling of the Y-lasers made by Alcatel SEL [32]. Following these early versions of XPM gates, an impressive activity on monolithic integration of interferometric gates has taken place [33]-[39], making these gates one of the test grounds for monolithic integration of active optical elements. 


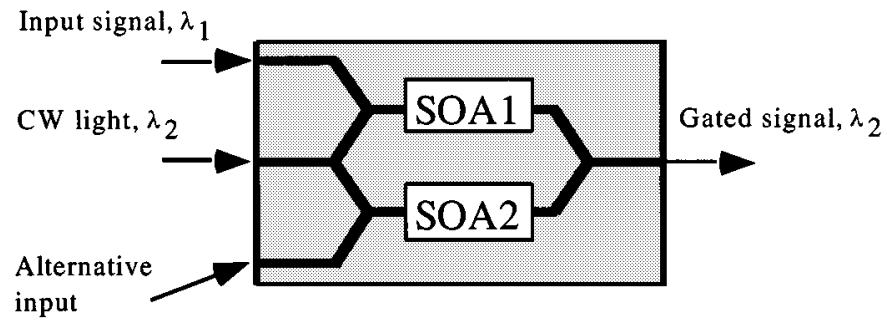

(a)

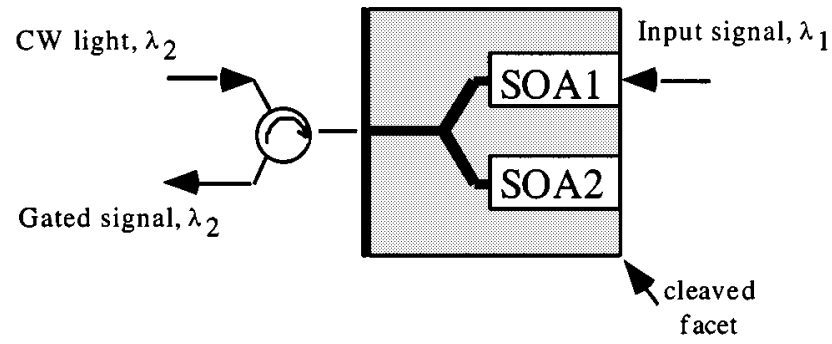

(b)

Fig. 3. Optical gates using MZI and MI structures with SOAs in the interferometer arms.

As mentioned, the Mach-Zehnder structures started with two-port devices, but now they have been developed into structures with separate waveguides for coupling the input signal into only one of the interferometer arms, as shown in Fig. 3(a). The idea is that the input signal depletes the carrier concentration in only one of the SOAs, thereby creating the wanted phase difference between the two interferometer arms in a very efficient way [34]-[37].

The Mach-Zehnder gate has even been refined using bimodal waveguide structures [39]. They allow the input signal and the probe signal to co-propagate in the structure using different spatial modes. Structures including integrated $\mathrm{CW}$ light sources and structures with integrated optical preamplifiers are also reported [40], [41].

Michelson interferometric gates have simpler structure since they offer direct access for the input signal to the SOAs [30], cf. Fig. 3(b). The MI converter has a reflective facet, making it a folded version of the MZI converter. Nonlinear loop mirror configurations with SOAs like the SLALOM (semiconductor laser amplifier loop mirror) and the TOAD (terahertz optical asymmetrical demultiplexer) are also reported [38], [42]-[44]. Such gates have the advantage of being inherently balanced, but only RZ signals can be handled. Another interferometric scheme that has been used in experiments is the UNI that requires only a single SOA [60].

Hybrid integration of SOAs on Si-PLCs has been reported as an alternative to the monolithic integration of the interferometric gates [45]. The approach is interesting since waveguide technology in $\mathrm{Si}$ is relatively mature.

The interferometric converters have the advantage of very steep transfer functions enabling extinction-ratio regeneration of the gated signals. Only small input-signal levels are needed to introduce a $\pi$ phase difference between the interferometer arms, so that a very efficient conversion is obtained almost independently of wavelength. Because of the small modulation associ-
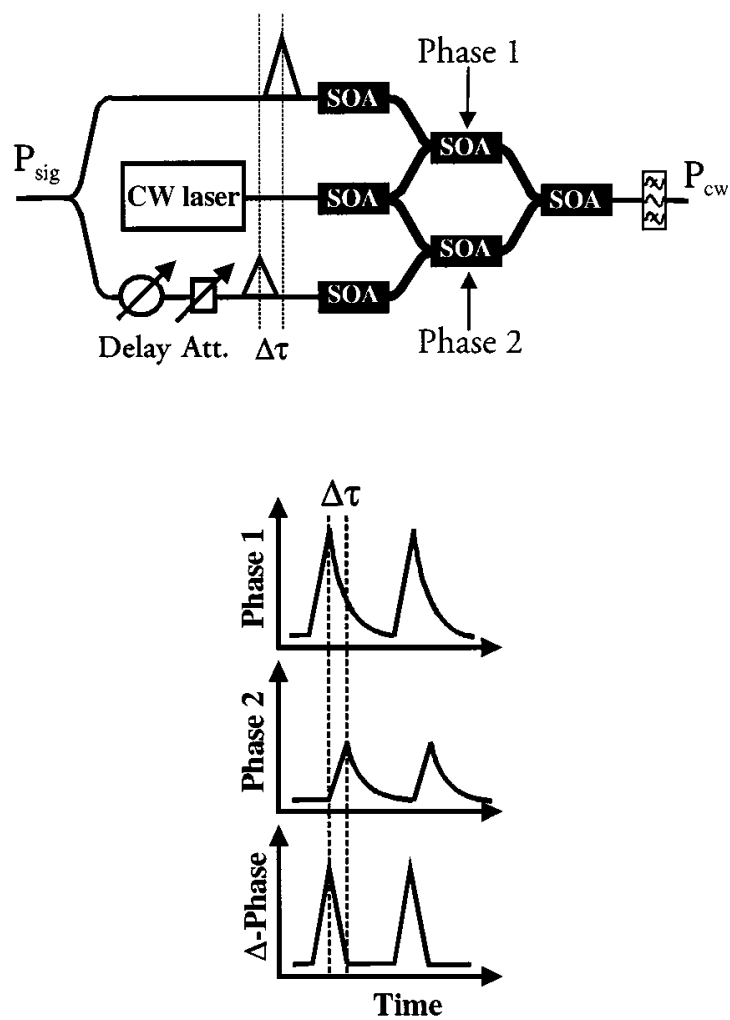

Fig. 4. Schematic for differential operation of Mazh-Zehnder gate to create short-switching windows.

ated with the $\pi$ phase shift, the frequency chirp of the output signal will also be small compared to, e.g., the XGM converter [30], [46], [47].

Besides signal waveform and spectral reshaping, the interferometric gates have high optical SNR ratios for the output signals. Moreover, the noise is redistributed due to the transfer function [48], [49]. As a result, the noise is accumulating less rapidly than for a chain of optical amplifiers. This allows for cascading of several gates [50]. The regenerative properties of the interferometric gates are important for construction of all-optical cross connects, in which other components-like amplifiers may degrade the signal quality.

Like the XGM gates, the interferometric XPM gates have achieved high-speed operation. Thus, wavelength conversion at $100 \mathrm{~Gb} / \mathrm{s}$ was recently achieved in a Mach-Zehnder structure [51].

Even faster operation can be achieved with the interferometric structures by controlling both arms of the interferometer in a differential way, as shown in Fig. 4, thereby creating very short switching windows (e.g., [52] and [53]) as is demonstrated experimentally in Fig. 5 [54]. It is clearly seen that the trailing edges become steep when the differential scheme is applied. Gates operated in the differential configuration have successfully been used for time demultiplexing from 160 to $10 \mathrm{~Gb} / \mathrm{s}$. Moreover, very elegant add-drop into an OTDM bit stream can be achieved with a Mach-Zehnder interferometer [55]. An extension of the add-drop experiment to $80 \mathrm{~Gb} / \mathrm{s}$ (also using the Mach-Zehnder from ETH) is shown in Fig. 6 [56]. Recently, the differential-control scheme has also been used to demonstrate wavelength conversion at an impressive bit rate of 


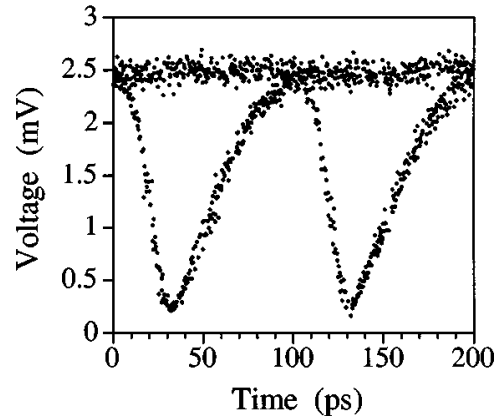

(a)

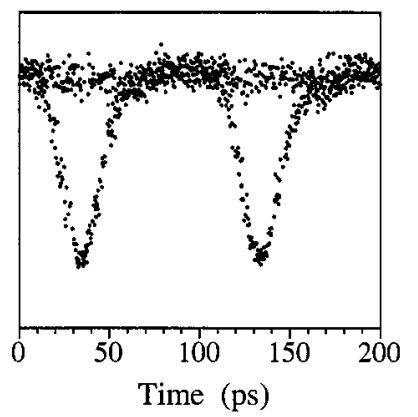

(b)

Fig. 5. Examples of gated output waveforms (a) without and (b) with differential control applied [54].

$168 \mathrm{~Gb} / \mathrm{s}$ [57]. High-speed operation has also been achieved, using nonlinear loop mirrors with SOAs demonstrating demultiplexing from $250 \mathrm{~Gb} / \mathrm{s}$ [58]. For demultiplexing of OTDM signals, the semiconductor-based interferometers do not yet achieve the speed of fiber-based NOLMs (e.g., [59]), but they have the advantage of being very compact and therefore potentially simpler to use in real systems.

The first packaged MZI structures have already been realized and tested in field trials. It should be noted that the gates still need refinement and as does the schemes for control of their operating point, but it is interesting to see how fast the development of these advanced optical gates has been since the start around 1993. The interferometric SOA gates have turned out to be important building blocks for development of all-optical regenerators and simple signal-processing elements as described below.

\section{FOUR-WAVE MiXING IN SOAs}

Instead of the cross-gain and cross-phase modulation in SOAs, it is also possible to utilize four-wave mixing (FWM). In fact, impressive work on wavelength conversion with FWM in SOAs was published already in 1989 [61] and numerous results have been published since then. The FWM scheme (see Fig. 7) is inherently fast and the gates have the advantage that many WDM channels can be handled simultaneously [62].

The input-to-output signal efficiency of the gate decreases with the wavelength separation of the pump and the input signal, but experiments using SOA gates with very long cavities have resulted in conversion efficiencies approaching $0 \mathrm{~dB}$ [63], which is important for good optical SNR at the output.

Clearly, the output signal wavelength depends on both the pump $\left(\lambda_{p}\right)$ and the input signal $\left(\lambda_{i}\right)$ wavelengths, so the pump

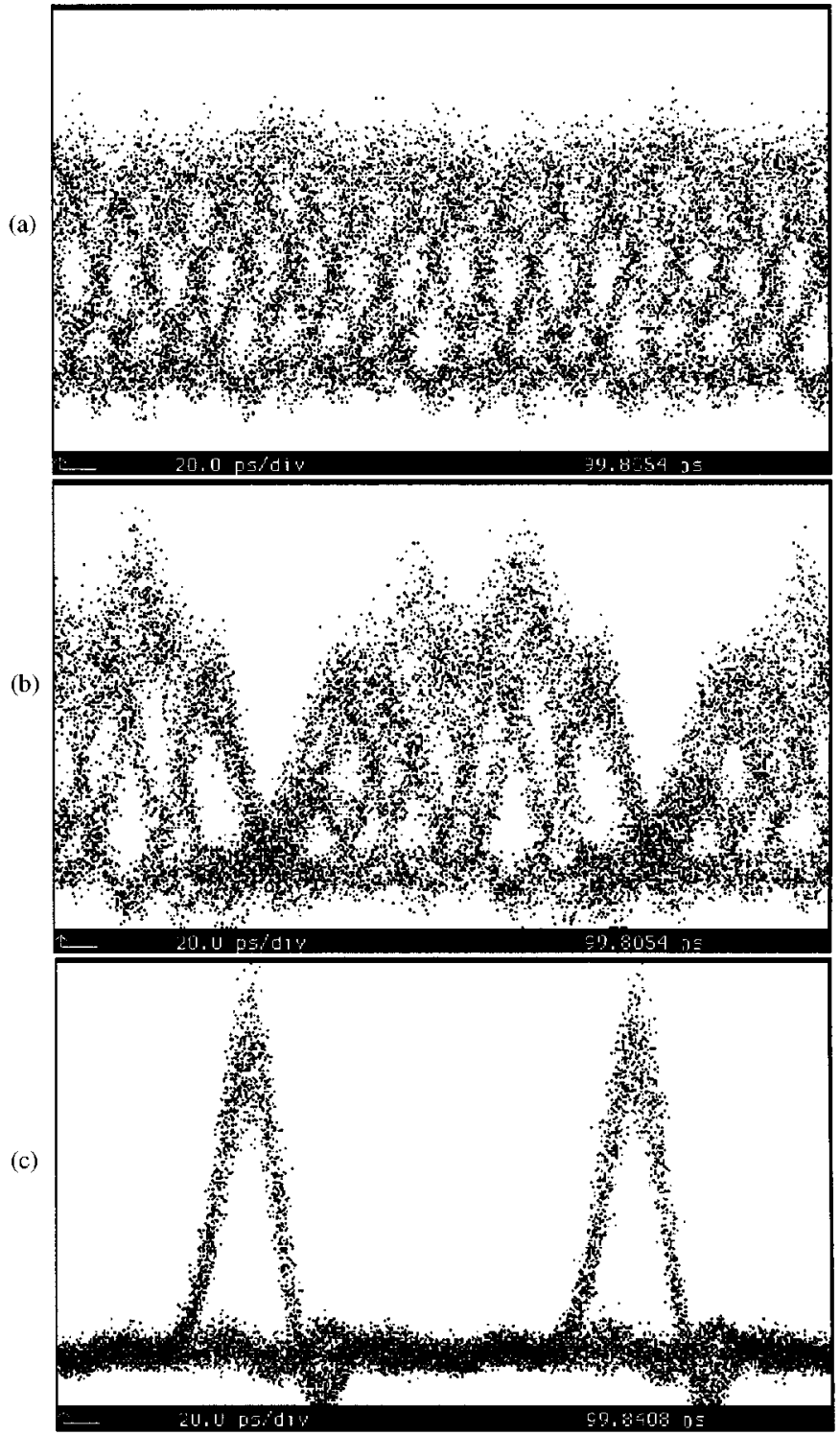

Fig. 6. Add-and-drop functionality at $80 \mathrm{~Gb} / \mathrm{s}$ using an SOA based Mach-Zehnder interferometer. Top trace is the $80 \mathrm{~Gb} / \mathrm{s}$ input signal (a), whereas the two lower traces show the $7 \times 10 \mathrm{~Gb} / \mathrm{s}$ signal with a vacated timeslot (b), and the dropped $10 \mathrm{~Gb} / \mathrm{s}$ signal (c) [56].

must be tunable even for converters with fixed output wavelength. Moreover, two pumps will be needed to ensure polarization-insensitive operation since the FWM process is polarization sensitive [62], [64]. Because of the relatively complex pumping scheme, FWM gates will probably only be used at bit rates above $100 \mathrm{~Gb} / \mathrm{s}$. Wavelength conversion at $100 \mathrm{~Gb} / \mathrm{s}$ has been achieved for conversion over 3.2-nm wavelength [65] and impressive results have also been achieved for conversion over larger wavelength spans. Examples are $40 \mathrm{~Gb} / \mathrm{s}$ over $24.6 \mathrm{~nm}$ [66], and $2.5 \mathrm{~Gb} / \mathrm{s}$ over $80 \mathrm{~nm}$ [67].

Also, time-demultiplexing from 100 to $10 \mathrm{~Gb} / \mathrm{s}$ is reported with FWM gates [68], and the gates have been used for clock extraction of a 6.3-GHz clock from a 400-Gb/s signal [69]. Another potentially important application is dispersion compensation by midspan spectral inversion where the optical phase conjugation of the FWM process is useful [70]. It should be noted that very impressive results on midspan spectral inversion have 

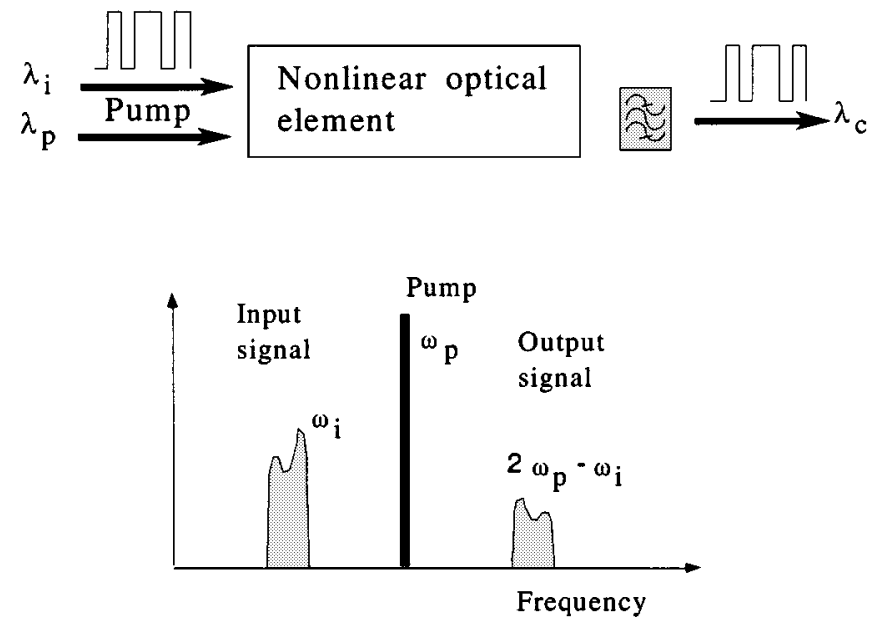

Fig. 7. Schematic of four-wave mixing gate.

also been reported using optical fiber as the nonlinear element [71].

\section{All-Optical 3-R Regenerators}

As the all-optical networks emerge, regenerators become key elements since signals experience different transmission paths in the network. Clearly, full 3-R regeneration is most attractive, but 2-R regeneration offering re-amplification and reshaping may also be useful. The interferometric (XPM) gates described above are well-suited for optical regeneration since they offer 2-R regenerating capabilities due to their nonlinear transfer function. Experiments with cascaded links have shown how these gates can redistribute noise caused by optical amplifiers and other network elements, and thereby ensure slower noise accumulation [72].

As shown schematically in Fig. 1(b), full regeneration can be achieved by using the input signal to gate extracted optical-clock pulses [73]-[75] and, in some cases, even better performance may be achieved with more refined use of both input arms of the interferometers, as illustrated in Fig. 8 [76]. The optical clock can be extracted optically for example with mode-locked or selfpulsating lasers [77], but combinations with electronic clockrecovery units is clearly also a solution to be considered [78]. As described above, the SOA-based gates can achieve data rates exceeding $100 \mathrm{~Gb} / \mathrm{s}$, so it should be possible to realize very fast optical regenerator units.

Fine examples of two-stage optical regenerators are also published. In one of the first reports [79], an XGM gate is used in the first stage to sample the input signal with extracted clock pulses and to equalize input power fluctuations. In the second stage, a Mach-Zehnder interferometric gate is used to regenerate the extinction ratio, resulting in complete regeneration. The scheme has been demonstrated for cascading a number of 140-km links in a $10 \mathrm{~Gb} / \mathrm{s}$ loop experiment, thereby allowing for transmission over more than $200000 \mathrm{~km}$ of fiber [80]. It should be noted that the regeneration is associated with wavelength conversion, so the regeneration can be combined with wavelength switching functionality. A two-stage regenerator arrangement can also be used for simultaneous synchronization of bit streams as described in [81].

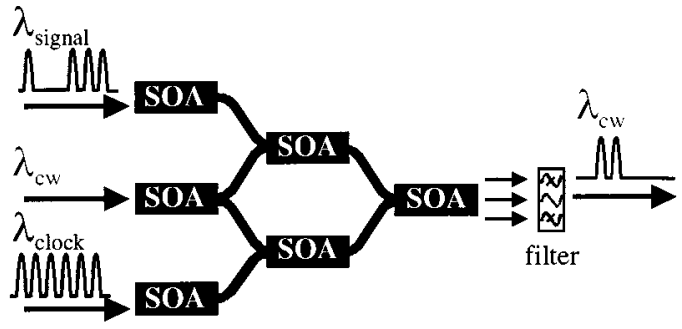

Fig. 8. Scheme for improved optical regeneration using the Mach-Zehnder interferometer as an inverting AND gate [76].

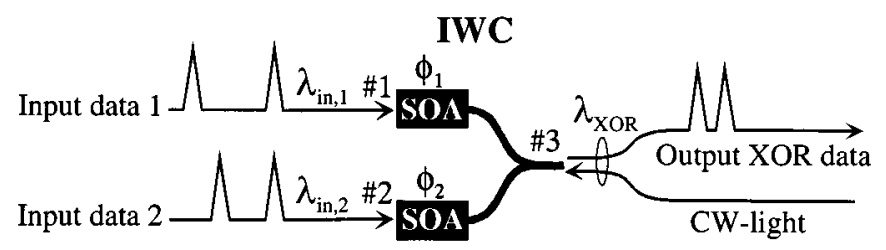

(a)

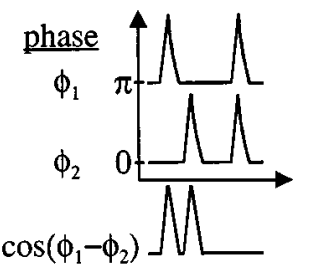

(b)

\begin{tabular}{||c|c|c||}
\hline \multicolumn{3}{|c||}{ Port number } \\
\hline $\begin{array}{c}\# 1 \\
\text { (IN1) }\end{array}$ & $\begin{array}{c}\# 2 \\
\text { (IN2) }\end{array}$ & $\begin{array}{c}\# 3 \\
\text { (XOR) }\end{array}$ \\
\hline 0 & 0 & 0 \\
\hline 0 & 1 & 1 \\
\hline 1 & 0 & 1 \\
\hline 1 & 1 & 0 \\
\hline
\end{tabular}

(c)

Fig. 9. Schematic of Michelson interferometer used as an XOR gate, including the detailed operation principle (b) and the XOR truth table (c) [89].

\section{All-OpticAl LOGiCAl Gates}

As the switch nodes in optical networks get more optical functions on board, it becomes desirable also to be able to do simple all-optical logic operations. Early experiments with alloptical logics were based on fiber nonlinear-loop mirrors, e.g., [82], [83], but similar functionality can be achieved with interferometric gates using SOAs as the nonlinear element [84], [85].

The XOR gate is of special interest since it is the basic building block for a wide range of functions. Clearly, the gates should operate at high bit rate to be competitive to their electronic counterparts. High-speed XOR gates based on loop and UNI configurations are reported in [86] and [87], while integrated versions based on XPM gates are reported in [88] and [89]. The function of the XPM gate used as an XOR gate is shown schematically in Fig. 9 [89]. The data signals launched into the two SOAs causes a phase modulation $(\phi)$ of the $\mathrm{CW}$-light propagating in the SOAs. At the output of the interferometer, the $\mathrm{CW}$ light from the two SOAs interferes either constructively or destructively, depending on the phase difference between the two arms. This 


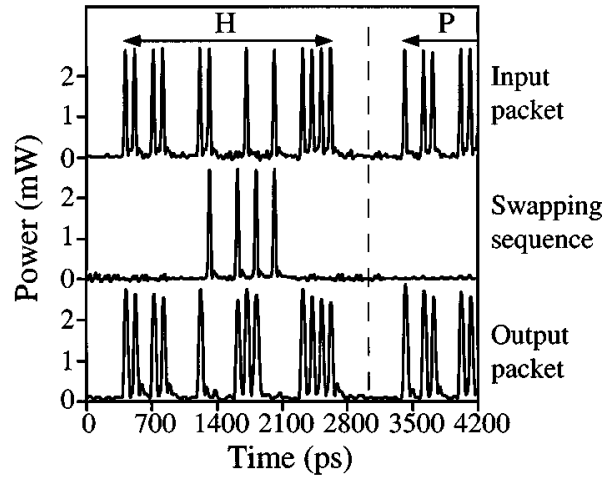

Fig. 10. Experimental demonstration of header replacement by XOR gate using a swapping sequence. Measured input and output packet sequences show header $(\mathrm{H})$ and parts of the payload $(\mathrm{P})[90]$.

leads to logical XOR of the two input data signals, as indicated by the truth table also shown in Fig. 9. Although the XOR gates are demonstrated at up to $20 \mathrm{~Gb} / \mathrm{s}$, they have the potential of much higher data rates as discussed above.

As an example of an application, Fig. 10 shows the experimental demonstration of an XOR gate used for optical label swapping at $10 \mathrm{~Gb} / \mathrm{s}$ [90]. Using a simple swapping sequence, only the necessary changes in the header section are made, while the package as a whole undergoes wavelength conversion at the same time. It is seen how the use of the XOR gate eliminates the need for guard bands between header and payload, thereby bringing optical packet-switched networks one step closer to a practical implementation.

Reports on more complex functions based on XOR gates realized from TOADs [43] are found in reports by BT Laboratories. Examples of their work include binary counters and parity checkers [91], [92]. No doubt all-optical logic for optical networks is an exciting field of research where we can expect much innovation.

\section{CONCLUSION}

SOAs have become useful building blocks for all-optical signal processing. From the early 1990s, the SOA-based structures have been developed into monolithically integrated interferometric optical gates that offer many advantages, such as signal reshaping and noise suppression. Experimentally, it is shown that these gates can operate as wavelength converters and OTDM demultiplexers at bit rates in excess of $100 \mathrm{~Gb} / \mathrm{s}$. It will be a continuing challenge to reach even higher bit rates by the use of, e.g., new materials such as quantum dot material.

It is also a challenge to build these gates into next generation all-optical 3R regenerators and to use them as logic gates that can perform simple operations in the switch nodes of the all-optical networks. Very fine work is now emerging in the literature, but there is a long way to go before we are close to the capability of electronic signal processing built into switch nodes today. Thus, we have much interesting research ahead to improve the optical technology. Moreover, we will need careful networks and systems studies to understand the role sharing between optical and electronic building blocks in the networks.

\section{ACKNOWLEDGMENT}

The author is grateful for the collaboration with both present and former colleagues at the Technical University of Denmark as well as colleagues in a number of European projects. H.N. Poulsen, T. Fjelde, and D. Wolfson of Research Center COM are acknowledged for their help with material.

\section{REFERENCES}

[1] J. C. Simon, "Semiconductor laser amplifier for single mode optical fiber communications," J. Opt. Commun., vol. 4, no. 2, pp. 51-62, 1983.

[2] T. Saitoh and T. Mukai, "1.5 $\mu \mathrm{m}$ GaInAsP traveling-wave semiconductor laser amplifier," IEEE J. Quantum Electron., vol. QE-23, pp. 1010-1020, June 1987.

[3] T. Durhuus, B. Fernier, P. Garabedian, F. Leblond, J. L. Lafragette, B. Mikkelsen, C. G. Joergensen, and K. E. Stubkjaer, "High speed alloptical gating using two-section semiconductor optical amplifier structure," in Proc. CLEO'92, Anaheim, CA, 1992, pp. 552-554.

[4] B. Glance, J. M. Wiesenfeld, U. Koren, A. H. Gnauck, H. M. Presby, and A. Jourdan, "High performance optical wavelength shifter," Electron. Lett., vol. 28, no. 18, pp. 1714-1715, Aug. 1992.

[5] A. Jourdan, L. Berthelon, P. Bonno, F. Bruyére, M. Chbat, C. Coeurjolly, J. Y. Emery, P. Gavignet, E. Grard, C. Janz, A. Noury, G. Soulage, and T. Zami, "Fully reconfigurable WDM optical crossconnect: Feasibility validation and preparation of prototype crossconnect for ACTS 'OPEN' field trials," in Proc. ECOC'97, vol. 3, Edinburgh, UK, Sept. 1997, pp. $55-58$.

[6] R. E. Wagner, R. C. Alferness, A. A. M. Saleh, and M. S. Goodman, "MONET: Multiwavelength optical networking (invited paper)," J. Lightwave Technol., vol. 14, pp. 1349-1355, June 1996.

[7] M. Berger, M. Chbat, P. Demeester, P. Godsvang, B. Hein, M. Huber, A. Jourdan, A. Leclert, R. Marz, T. Olsen, M. Sotom, G. Tobolka, B. Van Caenegem, and T. Broeck, "Pan-European optical networking using wavelength division multiplexing," IEEE Commun. Mag., vol. 35, pp. 82-89, Apr. 1997.

[8] K. Sato, S. Okamoto, and H. Hadama, "Network performance and integrity enhancement with optical path layer technologies," IEEE J. Select. Areas Commun., vol. 12, pp. 159-170, Jan. 1994.

[9] A. A. M. Saleh, "Transparent optical networks for the next generation information infrastructure," in Tech. Dig. OFC, San Diego, CA, 1995, p. 241.

[10] N. Wauters and P. Demester, "Wavelength routing algorithms for transparent optical networks," in Proc. ECOC, vol. 2, Brussels, Belgium, 1995, pp. 855-858.

[11] S. Subramaniam, M. Azizoglu, and K. Somani, "Effect of wavelength converter density on the blocking performance of all-optical networks," in Proc. LEOS Annu. Meeting, vol. 1, San Francisco, CA, Oct.-Nov. 1995, pp. 210-211.

[12] R. A. Barry and P. A. Humblet, "Models of blocking probability in alloptical networks with and without wavelength changers," in Proc. IEEE INFOCOM, vol. 1, Boston, MA, 1995, pp. 402-412.

[13] M. Kovacevic and A. Acampora, "On wavelength translation in all-optical networks," in Proc. IEEE INFOCOM, vol. 1, Boston, MA, 1995, pp. 413-422.

[14] W. D. Zhong et al., "Wavelength interchange devices as basic building blocks for multiwavelength cross-connects," in Proc. Photonics in Switching, Sendai, Japan, 1996, pp. 110-111.

[15] A. D. Ellis, A. E. Kelly, D. Nesset, D. Pitcher, D. G. Moodie, and R. Kashyap, "Error free $100 \mathrm{~Gb} / \mathrm{s}$ wavelength conversion using grating assisted cross gain modulation in a $2 \mathrm{~mm}$ long semiconductor amplifier," Electron. Lett., vol. 34, pp. 1958-1959, 1998.

[16] K. L. Hall and K.A. Rauschenbach, "Fiber optics and optical communications-100-Gb/s bitwise logic," Opt Lett., vol. 23, no. 16, pp. 1271-1273, 1998.

[17] N. Storkfelt, B. Mikkelsen, D. S. Olesen, M. Yamaguchi, and K. E. Stubkjaer, "Measurement of carrier lifetime and linewidth enhancement factor for $1.5-\mu \mathrm{m}$ ridge-waveguide laser amplifier," IEEE Photon. Technol. Lett., vol. 3, pp. 632-634, July 1991.

[18] T. Durhuus, B. Mikkelsen, C. Joergensen, and K. E. Stubkjaer, "All optical wavelength conversion by semiconductor optical amplifiers," J. of Lightwave Technol., vol. 14, pp. 942-954, June 1996. 
[19] F. Romstad, P. Borri, S. Bischoff, J. Mørk, W. Langbein, and J. M. Hvam, "Sub-picosecond pulse distortion in an InGaAsP optical amplifier," in Proc. European Conf. Optical Communication (ECOC), vol. II, Nice, France, 1999, pp. 28-29.

[20] A. Jourdan, G. Soulage, G. Da Loura, B. Clesca, P. Doussiere, C. Duchet, D. Leclert, J. F. Vinchart, and M. Sotom, "Experimental assessment of a $4 \times 4$ four-wavelength all-optical cross-connect at a $10-\mathrm{Gb} / \mathrm{s}$ line rate," in Tech. Dig. OFC'95, San Diego, CA, 1995, pp. 277-278.

[21] D. Chiaroni, P. Gavignet-Morin, P. A. Perrier, S. Ruggeri, S. Gauchard, D. Boudard, J. J. Jacquinot, C. Chauzat, J. Jacquet, P. Doussiere, M. Monot, E. Grard, D. Leclert, M. Sotom, J. M. Gabriagues, and J. Benoit, "Rack-mounted $2.5 \mathrm{~Gb} / \mathrm{s}$ ATM photonic switch demonstrator," in Proc. ECOC '93, vol. 3, Montreux, Switzerland, 1993, pp. 77-80.

[22] D. Norte and A. E. Willner, "Multistage all-optical WDM-to-TDM-to-WDM and TDM-to-WDM-to-TDM data-format conversion and reconversion through $80 \mathrm{~km}$ of fiber and three EDFAs," IEEE Photon. Technol. Lett., vol. 7, pp. 1354-1356, Nov. 1995.

[23] _ - "All-optical data format conversions and reconversions between the wavelength and time domains for dynamically reconfigurable WDM networks," J. Lightwave Technol., vol. 14, pp. 1170-1182, June 1996.

[24] C. Joergensen, S. L. Danielsen, B. Mikkelsen, M. Vaa, K. E. Stubkjaer, P. Doussiere, F. Pommerau, L. Goldstein, R. Ngo, and M. Goix, "Alloptical $40 \mathrm{~Gb} / \mathrm{s}$ OTDM to $2 \times 20 \mathrm{~Gb} / \mathrm{s}$ WDM signal-format translation," Electron. Lett., vol. 32, pp. 1384-1386, Jul. 1996.

[25] E. Park, D. orte, and A. E. Willner, "Simultaneous all-optical packet-header replacement and wavelength shifting for a dynamically reconfigurable WDM network," IEEE Photon. Technol. Lett., vol. 7, pp. 810-812, July 1995 .

[26] D. J. Blumenthal, A. Carena, L. Rau, V. Curri, and S. Humphries, "Alloptical label swapping with wavelength conversion for WDM-IP networks with subcarrier multiplexed addressing," IEEE Photon. Technol. Lett., vol. 11, pp. 1497-1499, Nov. 1999.

[27] J. Jacquet, F. Serre, E. Gaumot-Goarin, C. Labourie, O. le Gouzigou, F. Gaborit, C. Fortin, and P. Pagnod, " $2.5 \mathrm{~Gb} / \mathrm{s}$ optical triggering with signal reshaping using bistable laser with proton bombarded saturable absorber," in Proc. ECOC '93, vol. 2, Montreux, Switzerland, Sept. 1993, pp. 293-296.

[28] K. Nonaka, "Digital signal regeneration with side-injection-light-controlled bistable laser diode as a wavelength converter," IEEE Photon. Technol. Lett., vol. 7, pp. 29-31, Jan. 1995

[29] T. Durhuus, C. Joergensen, B. Mikkelsen, R. J. S. Pedersen, and K. E. Stubkjaer, "All optical wavelength conversion by SOAs in a Mach-Zehnder configuration," IEEE Photon. Technol. Lett., vol. 6, pp. 53-55, Jan. 1994.

[30] B. Mikkelsen, T. Durhuus, C. Joergensen, R. J. S. Pedersen, S. L. Danielsen, K. E. Stubkjaer, M. Gustavsson, W. van Berlo, and M. Janson, " $10 \mathrm{~Gb} / \mathrm{s}$ wavelength converter realized by monolithic integration of semiconductor optical amplifiers and Michelson interferometer," in Proc. ECOC, vol. 4, Florence, Italy, Sept. 1994, pp. 67-70.

[31] M. Gustavsson, B. Lagerstrom, L. Thylen, M. Janson, L. Lundgren, A.-C. Morner, M. Rask, and B. Stoltz, "Monolithically integrated $4 \times$ 4 InGaAsP/InP laser amplifier gate switch arrays," Electron. Lett., vol. 28 , no. 24, pp. 2223-2225, 1992

[32] M. Schilling, T. Durhuus, C. Joergensen, E. Lach, D. Baums, K. Daub, W. Idler, D. Laube, K. Stubkjaer, and K. Wünstel, "Monolithic Mach-Zehnder interferometer based optical wavelength converter operated at $2.5 \mathrm{~Gb} / \mathrm{s}$ with extinction ratio improvement and low penalty," in Proc. ECOC, vol. 2, Florence, Italy, Sept. 1994, pp. 647-650.

[33] N. Vodjdani, F. Ratovelomanana, A. Enard, G. Glastre, D. Rondi, R. Blondeau, T. Durhuus, C. Joergensen, B. Mikkelsen, and K. E. Stubkjaer, "All optical wavelength conversion with SOAs monolithically integrated in a passive Mach-Zehnder interferometer," in Proc. ECOC, vol. 4, Florence, Italy, Sept. 1994, pp. 95-98.

[34] M. Schilling, K. Daub, W. Idler, D. Baums, U. Koerner, E. Lach, G. Laube, and K. Wunstel, "Wavelength conversion based on integrated all-active three-port Mach-Zehnder interferometer," Electron. Lett., vol. 30, pp. 2128-2130, Dec. 1994.

[35] N. Vodjdani, F. Ratovelomanana, A. Enard, G. Glastre, D. Rondi, R. Blondeau, C. Joergensen, S. L. Danielsen, T. Durhuus, B. Mikkelsen, and K. E. Stubkjaer, "Integrated optics all optical wavelength converter," in Proc. ECIO'95, Delft, The Netherlands, Apr. 1995, pp. 261-266.

[36] F. Ratovelomanana, N. Vodjdani, A. Enard, G. G. A. D. Ellis, A. E. Kelly, D. Nesset, D. Pitcher, D. G. Moodie, and R. Kashyap, "An all-optical wavelength-converter with semiconductor optical amplifiers monolithically integrated in a asymmetric passive Mach-Zehnder interferometer," IEEE Photon. Technol. Lett., vol. 7, pp. 992-994, Sept. 1995.
[37] X. Pan, J. M. Wiesenfeld, J. S. Perino, T. L. Koch, G. Raybon, U. Koren, M. Chien, M. Young, B. I. Miller, and C. A. Burrus, "Dynamic operation of a three-port, integrated Mach-Zehnder wavelength converter," IEEE Photon. Technol. Lett., vol. 7, pp. 995-997, Sept. 1995.

[38] E. Jahn, N. Agrawal, W. Pieper, H.-J. Ehrke, D. Franke, W. Fürst, and C. M. Weinert, "Monolithically integrated nonlinear Sagnac interferometer and its application as a $20 \mathrm{~Gb} / \mathrm{s}$ all-optical demultiplexer," Electron. Lett., vol. 32, pp. 782-783, 1996.

[39] C. Janz, F. Poingt, F. Pommereau, F. Gaborit, D. Ottenwlder, I. Guillemot, B. Dagens, and M. Renaud, "All-active dual-order mode Mach-Zehnder wavelength converter for power-efficient, co-propagative operation," in Proc. ECOC'98, Madrid, Spain, 1998, pp. 661-662.

[40] L. H. Spiekman, U. Koren, M. D. Chien, B. I. Miller, J. M. Wiesenfeld, and J. S. Perino, "All-optical Mach-Zehnder wavelength converter with monolithically integrated DFB probe source," IEEE Photon. Technol. Lett., vol. 9, pp. 1349-1351, Oct. 1997.

[41] L. H. Spiekman, J. M. Wiesenfeld, U. Koren, B. I. Miller, and M. D. Chien, "All-optical Mach-Zehnder wavelength converter with monolithically integrated preamplifiers," IEEE Photon. Technol. Lett., vol. 10, pp. 1115-1117, Aug. 1998

[42] M. Eiselt, W. Pieper, and H. G. Weber, "Decision gate for all-optical data retiming using a semiconductor laser amplifier in a loop mirror configuration," Electron. Lett., vol. 29, no. 1, pp. 107-109, 1993.

[43] J. P. Sokoloff, P. R. Prucnal, I. Glesk, and M. J. Kane, "A terahertz optical asymmetric demultiplexer (TOAD)," IEEE Photon. Technol. Lett., vol. 7, pp. 787-790, May 1993

[44] D. A. O. Davies, A. D. Ellis, and G. Sherlock, "Regenerative $20 \mathrm{~Gb} / \mathrm{s}$ wavelength conversion and demultiplexing using a semiconductor laser amplifier nonlinear loop mirror," Electron. Lett., vol. 31, pp. 1000-1001, June 1995.

[45] R. Sato, Y. Sakai, S. Sekine, Y. Tohmori, Y. Inoue, K. Shuto, M. Yamada, and T. Kanamori, "Hybrid integrated wavelength converter module using spot-size converter integrated semiconductor optical amplifier array on a PLC platform," in Proc. OECC'97, Seoul, Korea, July 1997, paper 9C3-3.

[46] T. Durhuus, C. Joergensen, B. Mikkelsen, K. E. Stubkjaer, F. Ratovelomanana, A. Enard, G. Glastre, N. Vodjani, and P. Pagnod, "Monolithic integrated Mach-Zehnder wavelength converter: Conversion and transmission experiments at $5 \mathrm{~Gb} / \mathrm{s}$," in Tech. Dig. OFC '95, San Diego, Feb. 1995, paper TuO6.

[47] W. Idler, M. Schilling, K. Daub, D. Baums, U. Korner, E. Lach, G. Laube, and K. Wunstel, "Signal quality and BER performance improvement by wavelength conversion with an integrated three-port Mach-Zehnder interferometer," Electron. Lett., vol. 31, pp. 454-455, Mar. 1995.

[48] X. Pan and T. L. Koch, "Intensity noise characteristics of a Mach-Zehnder wavelength converter," IEEE Photon. Technol. Lett., vol. 7, pp. 1276-1278, Nov. 1995.

[49] B. Mikkelsen, S. L. Danielsen, C. Joergensen, R. J. S. Pedersen, H. N. Poulsen, and K. E. Stubkjaer, "All-optical noise reduction capability of interferometric wavelength converters," Electron. Lett., vol. 32, pp. 566-567, Mar. 1996.

[50] J. M. Wiesenfeld, J. S. Perino, T. L. Koch, G. Raybon, U. Koren, M. Chien, M. Young, B. I. Miller, C. A. Burrus, K. L. Hall, J. C. Livas, and G. Raybon, "Transmission through 10 all-optical interferometric wavelength converter spans," in Tech. Dig. OFC'96, San Jose, CA, Feb. 1996, post deadline paper PD13.

[51] J. Leuthold, B. Mikkelsen, G. Raybon, C. H. Joyner, J. L. Pleumeekers, B. I. Miller, K. Dreyer, and C. A. Burrus, "All-optical wavelength conversion up to $100 \mathrm{~Gb} / \mathrm{s}$ with SOA delayed-interference configuration," in Proc. ECOC 2000, vol. 3, Munich, Germany, Sept. 2000, pp. 119-120.

[52] S. Nakamura, K. Tajima, and S. Nakamura, "Experiamental investigation on high speed switching characteristics of a novel symmetric Mach-Zehnder all-optical switch," Appl. Phys. Lett., vol. 65, pp. 283-285, 1994

[53] B. Mikkelsen, K. S. Jepsen, M. Vaa, H. N. Poulsen, K. E. Stubkjaer, R. Hess, M. Duelk, W. Vogt, E. Gamper, E. Gini, P. A. Besse, H. Melchior, S. Bouchoule, and F. Devaux, "All-optical wavelength converter scheme for high speed RZ signal formats," Electron. Lett., vol. 33, pp. 2137-2139, 1997.

[54] D. Wolfson, private communication, Sept. 2000.

[55] S. Fischer, M. Dulk, E. Gamper, W. Vogt, W. Hunziker, E. Gini, H. Melchior, A. Buxens, H. N. Poulsen, and A. T. Clausen, "All-optical regenerative OTDM add-drop multiplexing at $40 \mathrm{~Gb} / \mathrm{s}$ using monolithic InP Mach-Zehnder interferometer," IEEE Photon. Technol. Lett., vol. 12, pp. 335-337, Mar. 2000. 
[56] H. N. Poulsen, A. T. Clausen, A. Buxens, L. Oxenloewe, C. Peucheret, C. Rasmussen, F. Liu, J. Yu, A. Kloch, T. Fjelde, D. Wolfson, and P. Jeppesen, "Ultra fast all-optical signal processing in semiconductor and fiber based devices," in Proc. ECOC 2000, vol. 3, Munich, Germany, Sept. 2000, pp. 63-64.

[57] Y. Ueno, S. Nakamura, H. Hatakeyama, T. Tamanuki, T. Sasaki, and K. Tajima, "168 Gb/s OTDM wavelength conversion using an SMZ-type all-optical switch," in Proc. ECOC 2000, vol. 1, Munich, Germany, Sept. 2000, pp. 13-14.

[58] I. Glesk, J. P. Sokoloff, and P. R. Prucnal, "Demonstration of all-optical demultiplexing of TDM data at $250 \mathrm{~Gb} / \mathrm{s}$," Electron. Lett., vol. 30, no. 4, pp. 339-341, 1994.

[59] T. Yamamoto, E. Yoshida, and M. Nakazawa, "Ultrafast nonlinear optical loop mirror for demultiplexing $640 \mathrm{~Gb} / \mathrm{s}$ TDM signals," Electron. Lett., vol. 34, no. 10, pp. 1013-1014, 1998.

[60] N. S. Patel, K. A. Rauschenbach, and K. L. Hall, " 40 Gb/s demultiplexing using an ultrafast nonlinear interferometer (UNI)," IEEE Photon. Technol. Lett., vol. 8, no. 12, pp. 1695-1697, 1996.

[61] G. Grosskopf, R. Ludwig, R. Schnabel, and H. G. Weber, "Frequency conversion with semiconductor laser amplifiers for coherent optical frequency division switching," presented at IOOC '89, Paper 19C4-4, Kobe, Japan, July 1989.

[62] R. Schnabel, U. Hilbk, T. Hermes, P. Meissner, C. Helmolt, K. Magari, F. Raub, F. W. Pieper, F. J. Westphal, R. Ludwig, L. Kuller, and H. G. Weber, "Polarization insensitive frequency conversion of a 10-channel OFDM signal using four-wave mixing in a semiconductor laser amplifier," IEEE Photon. Technol. Lett., vol. 6, pp. 56-58, Jan. 1994.

[63] F. Martelli, "Semiconductor optical amplifiers for very efficien frequency conversion by four-wave mixing," presented at IQEC '96, Paper ThN2, Sydney, Australia, July 1996.

[64] R. M. Jopson and R. E. Tench, "Polarization-independent phase conjugation of lightwave signals," Electron. Lett., vol. 29, pp. 2216-2217, Dec. 1993.

[65] A. E. Kelly, A. D. Ellis, D. Nesset, R. Kashyap, and D. G. Moodie, "100 $\mathrm{Gb} / \mathrm{s}$ wavelength conversion using FWM in an MQW semiconductor optical amplifier," Electron. Lett., vol. 34, no. 20, pp. 1955-1956, 1998.

[66] A. E. Kelly, D. D. Marcenac, and D. Nesset, " $40 \mathrm{~Gb} / \mathrm{s}$ wavelength conversion over $24.6 \mathrm{~nm}$ using FWM in a semiconductor optical amplifier with an optimized MQW active region," Electron. Lett., vol. 33, no. 25, pp. 2123-2124, 1997.

[67] T. J. Morgan, R. S. Tucker, and J. P. R. Lacey, "All-optical wavelength translation over $80 \mathrm{~nm}$ at $2.5 \mathrm{~Gb} / \mathrm{s}$ using four-wave mixing in a semiconductor optical amplifier," IEEE Photon. Technol. Lett., vol. 11, pp. 982-984, Aug. 1999.

[68] S. Kawanishi, K. Okamoto, M. Ishii, O. Kamatani, H. Takara, and K. Uchiyama, "All-optical time-division- multiplexing of $100 \mathrm{~Gb} / \mathrm{s}$ signal based on four-wave mixing in a travelling-wave semiconductor laser amplifier," Electron. Lett., vol. 33, no. 11, pp. 976-977, 1997.

[69] O. Kamatani and S. Kawanishi, "Prescaled timing extraction from 400 $\mathrm{Gb} / \mathrm{s}$ optical signal using a phase lock loop based on four-wave-mixing in a laser diode amplifier," IEEE Photon. Technol. Lett., vol. 8, pp. 1094-1096, Aug. 1996.

[70] D. D. Marcenac, D. Nesset, A. E. Kelly, M. Brierley, A. D. Ellis, D. Moodie, and C. W. Ford, "40Gb/s transmission over 406km of NDSF using midspan spectral inversion by four-wave-mixing in a 2-mm-long semiconductor optical amplifier," Electron. Lett., vol. 33, pp. 879-880, 1997.

[71] S. Watanabe, S. Takeda, G. Ishikawa, H. Ooi, J. G. Nielsen, and C. Sonne, "Simultaneous wavelength conversion and optical phase conjugation of $200 \mathrm{~Gb} / \mathrm{s}(5 \times 40 \mathrm{~Gb} / \mathrm{s})$," in Proc. IOOC-ECOC'97, vol. 5 , Edinburgh, U.K., Sept. 1997, pp. 1-4.

[72] R. J. S. Pedersen, M. Nissov, B. Mikkelsen, H. N. Poulsen, K. E. Stubkjaer, M. Gustavsson, W. van Berlo, and M. Janson, "Transmission through a cascade of 10 all-optical interferometric wavelength converter spans at $10 \mathrm{~Gb} / \mathrm{s}$, , Electron. Lett., vol. 32, no. 11, pp. 1034-1035, May 1996.

[73] W. Pieper, K. Weich, R. Ludwig, E. Patzak, and H. G. Weber, "All-optical polarization and wavelength independent $3 \mathrm{R}$ signal regenerator," Electron. Lett., vol. 32, no. 14, pp. 1316-1317, 1996.

[74] L. Billes, J. C. Simon, B. Kowalski, M. Henry, G. Michaud, P. Lamuler and F. Alard, "20 Gb/s optical 3R regeneration using SOA-based Mach-Zehnder interferometer gate," in Proc. IOOC/ECOC, vol. 2 , Endinburgh, U.K., 1997, pp. 269-272.

[75] B. Lavigne, P. Guerber, D. Chiaroni, C. Janz, A. Jourdan, B. Sartorius, C. Bornholdt, and M. Morhle, "Test at $10 \mathrm{~Gb} / \mathrm{s}$ of an optical 3R regenerator using an integrated all-optical clock recovery," in Proc. ECOC, vol. 2, Nice, France, Sept. 1999, pp. 262-263.
[76] D. Wolfson, T. Fjelde, A. Kloch, C. Janz, F. Poingt, I. Guillemot, F. Gaborit, A. Coquelin, B. Dagens, and M. Renaud, "Novel scheme for alloptical wavelength conversion in SOA-based interferometric devices," presented at Optical Amplifiers and their Applications, Paper OWB5, Quebec, Canada, July 2000.

[77] B. Sartorius, C. Bornholdt, O. Brox, U. Feiste, and M. Mohrle, "Toward the all-optical 3R regenerator: Performance of the optical clock," in Proc. ECOC, vol. 2, Nice, France, Sept. 1999, pp. 264-265.

[78] S. Fischer, M. Dulk, E. Gamper, W. Vogt, E. Gini, H. Melchior, W. Hunziker, D. Nesset, and A. D. Ellis, "Optical 3R regenerator for $40 \mathrm{~Gb} / \mathrm{s}$ networks," Electron. Lett., vol. 35, no. 23, pp. 2047-2049, 1999.

[79] D. Chiaroni, B. Lavigne, A. Jourdan, L. Hamon, C. Janz, and M. Renauld, "New $10 \mathrm{~Gb} / \mathrm{s}$ 3R NRZ optical regenerative interface based on semiconductor optical amplifiers for all-optical networks," in Proc. IOOC/ECOC, vol. 5, Endinburgh, U.K., Sept. 1997, pp. 41-44.

[80] B. Lavigne, D. Chiaroni, L. Hamon, C. Janz, and A. Jourdan, "Performance and system margins at $10 \mathrm{~Gb} / \mathrm{s}$ of an optical repeater for long haul NRZ transmission," in Proc. ECOC '98, Madrid, Spain, Sept. 1998, pp. 559-560.

[81] K. S. Jepsen, A. T. Clausen, B. Mikkelsen, H. N. Poulsen, and K. E. Stubkjaer, "All-optical network interface for bit synchronization and regeneration," in Proc. IOOC/ECOC, vol. 5, Edinburgh, U.K., Sept. 1997, pp. $89-92$.

[82] M. Jinno and T. Matsumoto, "Ultrafast all-optical logic operations in a nonlinear Sagnac interferometer with two control beams," Opt. Lett., vol. 16, no. 4, pp. 220-222, 1991.

[83] K. L. Hall and K. A. Rauschenbach, "All-optical bit pattern generation and matching," Electron. Lett., vol. 32, no. 13, pp. 1214-1215, 1996.

[84] N. S. Patel, K. A. Rauschenbach, and K. L. Hall, " $40 \mathrm{~Gb} / \mathrm{s}$ cascadable all-optical logic using ultrafast nonlinear interferometer," presented at OFC'96, Paper PD14, San Jose, CA, Feb. 1996.

[85] A. J. Poustie, K. J. Blow, and R. J. Manning, "All-optical regenerative memory for long term data storage," Opt. Commun., vol. 140, no. 4-6, pp. 184-186, 1997.

[86] T. Houbavlis, K. Zoiros, A. Hatziefremidis, H. Avramopoulos, L. Occhi, G. Guekos, S. Hansmann, H. Burkhard, and R. Dall'Ara, "10 Gb/s alloptical Boolean XOR with SOA fiber Sagnac gate," Electron. Lett., vol. 35, no. 19, pp. 1650-1652, 1999.

[87] C. Bintjas, M. Kalyvas, G. Theophilopoulos, T. Stathopoulos, H. Avramopoulos, L. Occhi, L. Schares, G. Guekos, S. Hansmann, and R. Dall'Ara, "20 Gbps Boolean XOR with UNI gate," in Proc. ECOC'2000, vol. 4, Munich, Munich, Sept. 2000, pp. 61-62.

[88] L. Zucchelli, G. Bendelli, D. Raspollini, M. Puelo, P. Gambini, M. Schilling, W. Idler, and K. Wünstel, "All-optical EX-OR gate based on an integrated interferometric Mach-Zehnder wavelength converter," Proceedings of Photonics in Switching '97, Stockholm, Paper PFB3, Apr. 1997.

[89] T. Fjelde, D. Wolfson, A. Kloch, C. Janz, A. Coquelin, I. Guillemot, F. Gaborit, F. Poingt, B. Dagens, and M. Renaud, " $20 \mathrm{~Gb} / \mathrm{s}$ all-optical logic XOR using integrated interferometric wavelength converter," in Tech Dig. OAA’2000, Quebec City, PQ, Canada, 2000, pp. 189-191.

[90] T. Fjelde, A. Kloch, D. Wolfson, B. Dagens, A. Coquelin, I. Guillemot, F. Gaborit, F. Poingt, and M. Renaud, "Novel scheme for simple labelswapping employing logic XOR in an integrated interferometric wavelength converter," in Proc. ECOC, vol. 4, Munich, Germany, 2000, pp. 63-64.

[91] A. J. Poustie, K. J. Blow, A. E. Kelly, and R. J. Manning, "All-optical parity checker with bit-differential delay," Opt. Commun., vol. 162, pp. 37-43, 1999.

[92] — , "All-optical binary counter," in Proc. ECOC'99, vol. 1, Nice, France, Sept. 1999, pp. 246-247.

Kristian E. Stubkjaer was born in 1953 and received the M.Sc. and Ph.D. degrees.

After research experience at the Tokyo Institute of Technology, Tokyo, Japan, and the IBM T.J. Watson Research Center, Yorktown Heights, NY, he became a Faculty Member at the Technical University of Denmark, Lyngby, in 1983. His research has been in the field of active components for optical systems and networks. From 1985 to 1990 he was head of the Electromagnetics Institute. He served as Chairman of the Electrotechnical Committee under the Danish Technical Research Council (Danish Ministry for Research) from 1991 to 1997. Since 1998 he has been Director for Research Center COM, Technical University of Denmark. 